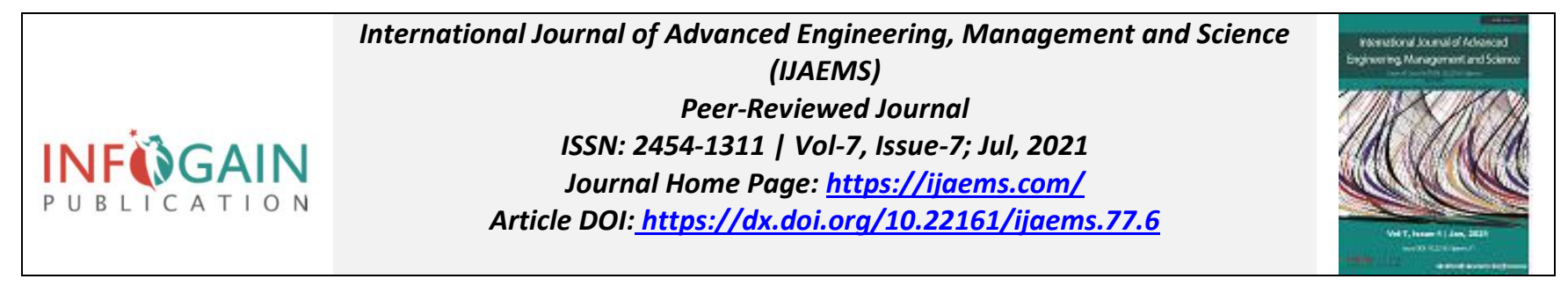

\title{
War Field Spying and Rifle Firing system with UGV's
} Approach

\author{
Asst. Prof. Ashitha V Naik, Balram Rayappa Kage, Vikrant Krishna, Tarun Pal, Tanmay \\ Raj
}

ECE Department, NITTE Meenakshi Institute of Technology, Bangalore, India

Received: 10 Jul 2021; Received in revised form: 17 Jul 2021; Accepted: 19 Jul 2021; Available online: 22 Jul 2021

\begin{abstract}
Our country has been through war since 1947, through the will of Indian soldiers to defend our country has led us to be victorious but we have lost many precious lives. At present our enemy has concentrated more on robotic based technology to counter us, although the love, courage and will does not imply to a robot, India has been emerging with latest technology like Agni missile to counter. War field spying robot with UGV's is the latest technology which most nations are associated with to defend the lives of their soldiers. Our robotic model has been designed such that it gives live location at server end to keep surveillance, empowered by PIC microcontroller and NodeMCU manually designed to give complete and hassle-free use. It's connected with IR sensor, bomb detector and buzzer. The IR sensor gives the hinderance information and bomb detector has been implied to fund underground mines. The server end connected through blynk gives all the information required. Thus, it can be very helpful only to counter the enemy but also to make strategic preparations in time of war.
\end{abstract}

Keywords-Surveillance, PIC microcontroller, NodeMCU, IoT controlled embedded system.

\section{INTRODUCTION}

The main aim of Defense is to protect the border and to confirm that no infiltrators or criminal enters our country. defence is deployed in terribly laborious and sensitive areas at Border also as for internal security duty. Keeping visible the realm of responsibility given to Defense and handiness of men, typically it's not in the least potential to protect some vulnerable purpose around the clock, at that point it becomes imperative to develop an electronic system through that the weapon are often operated remotely or mechanically. to beat this downside, we've got designed a singular system i.e., IOT controlled / auto firing device which may be sited at such places and is capable to fireplace automatically and remotely whenever any unwanted person enters an unattended purpose / place. In modern days, still we tend use the rifle for manual firing there's no automatic firing rifle out there in Defense and state police.

Here we've got designed one ROBOTIC model and automobile firing system, that provides automatic firing, This article can be downloaded from here: www.ijaems.com

(C)2021 The Author(s). Published by Infogain Publication. controlled by web. it's very helpful for Defense. Our country has been through war since post-independence. Though the will of our soldiers to protect the countrymen has led us to be victorious, but we have lost many precious lives. At present our enemies have concentrated more on robotic based technology to counter us all though the love courage and will does not imply to a robot, India has been emerging with latest technology (like Agni prime) to counter. The unmanned ground vehicle is counted as most emerging robotic warfare model in the interest of most countries. The aim was to build a prototype model capable of all time surveillance with upgraded hardware to counter a situation. The machine comprises of night-sight remote camera which may send recordings of the conflict field to hinder any damage and misfortune to human existence. Military people have an enormous danger on their lives while getting into an obscure domain. The robot can fill in as a material machine for the safeguard area to downsize the deficiency of human existence and can also thwart prohibit exercises. it'll work with every one of the tactical

This work is licensed under a Creative Commons Attribution 4.0 License. http://creativecommons.org/licenses/by/4.0/ 
people and military to get a handle on the state of the region prior to coming into it. The utilization of GPS is developing fast as of late. Not exclusively in military and science capacities, be that as it may also in common use, GPS assumes a critical part in a few frameworks.

\section{LITERATURE REVIEW}

[1]. Global positioning system have been used to any movable machine to locate, navigate, and control the motion. GPS guidance system enabled are working robotic model to do all these functions. GPS would be enabled by 8-bit NodeMCU and a simple android blynk application designed to control a low cost IoT devices is used at the receiver end to control.

[2]. Design and development of robotic model built on a steel frame with four DC motors common peripherals interface microcontroller and 8-bit NodeMCU was implemented. The PIC microcontroller is connected to DC motor to get the motion control. NodeMCU enables internet and GPS helping to send the information.

[3]. The low-cost implementation design was studied. The paper is basically about the connections of
UGV help us in relay connection and basic idea of UGV working model.

[4]. Haptic technology is used to get a wireless communication model which would help in working of robotic model. The idea was to save human from landmines, bombs and detect the threats so that the lives of human could be saved.

[5]. The paper shows the uses of wireless camera to give surveillance of live view. The threat can be viewed from these cameras and immediate action can be taken. Since Bluetooth have a limited range, we decide to get connected with robot by the help of internet. Mobile camera was to do low-cost implementation.

[6]. The implementation of 8-bit NodeMCU was taken in the view of getting connected to internet. The android blynk application is used for the controlling of vehicle with the help of DC motor connected to PIC, which is connected to NodeMCU which in turn receives the RF signal through blynk application.

\section{PROPOSED SYSTEM}

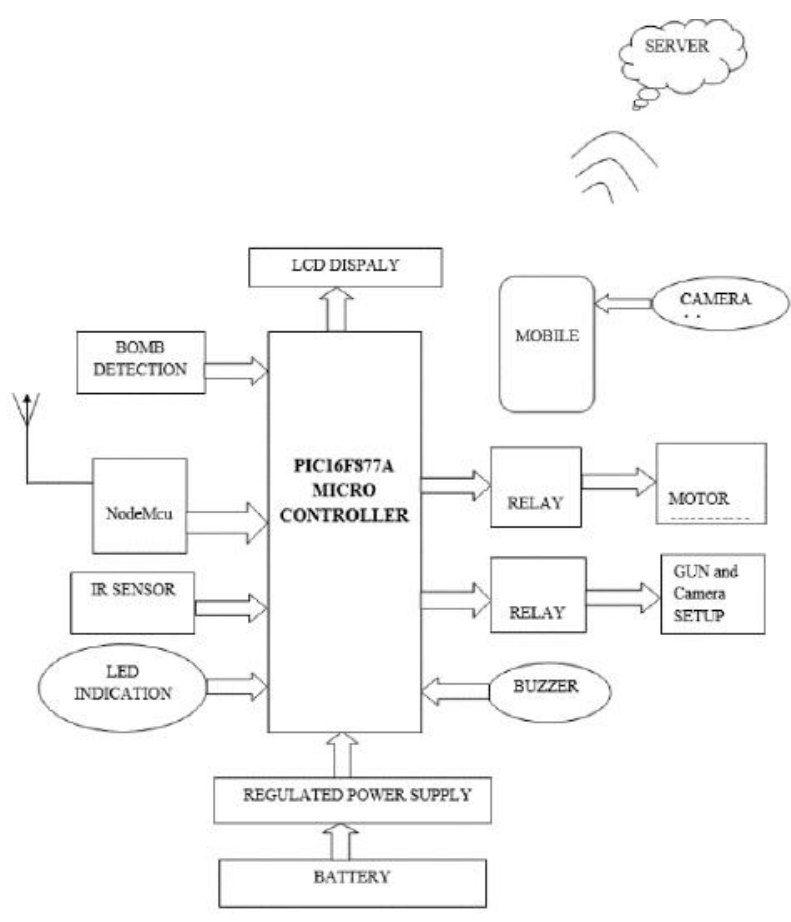

Fig.1: Block Diagram of Proposed System

The system consists of two parts, the rover and the user end. For the movement of UGV we are using Blynk android application which is integrated with NodeMCU through Arduino IDE. The construction of NodeMcu This article can be downloaded from here: www.ijaems.com controlled Robot consists of a frame which is used for mounting the components such as D.C motor, battery, and wheel. The front and back wheels are fitted in the base of the frame. The power for driving the motor is taken from 
the battery. The receiver circuit is fixed inside the vehicle. The receiver having four relays. These relays output is connected to the D.C motor. As soon as power supply is given to the system controller peripherals, timer, LCD, NodeMcu module will get initialize. NodeMcu module needs to be connected with android Blynk app in order to operate the vehicle and control the direction of gun and camera with triggering. There are different buttons to for every action like forward, reverse, left, right, stop, direction control of gun and triggering of bullet. Bomb detection sensor (Metal detector), IR sensor is connected to controller and controller keeps monitoring the sensor status. If Bomb detection sensor found any metal near to the sensor, then sensor output will go high, and controller detects, then the vehicle will stop and RED LED starts blinking at $250 \mathrm{msec}$ rate. After the blinking of LED one can identify using camera so that vehicle is stopped due to bomb detection. During the movement of vehicle, if IR sensor detects any object in front of the vehicle, then controller will stop and blinks the RED led's at $1 \mathrm{sec}$ rate. By seeing RED led blinking rate in the camera one can identify what is the status of the vehicle. In this system for triggering mechanism, gun ejector is used, once trigger button is pressed from transmitter side, receiver controller will give $1 \mathrm{sec}$ supply to the ejector, then ejector will pull back the trigger button in the gun. At that time bullet will come out to reach the target. The surveillance is done through IP webcam android application and putting the IP address in browser.

\section{RESULTS AND DISCUSSION}

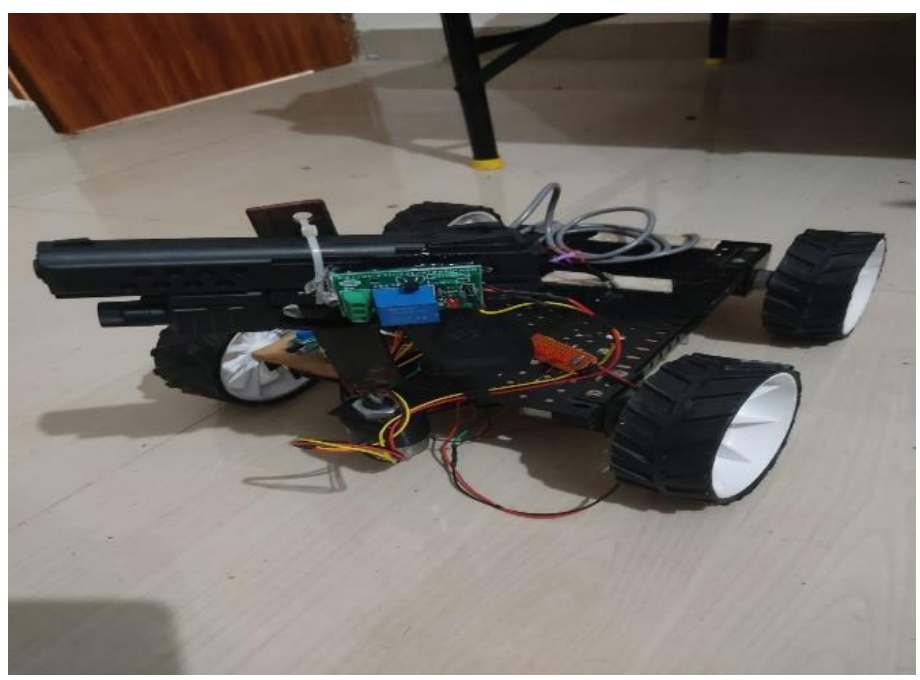

Fig -2 UGV Module

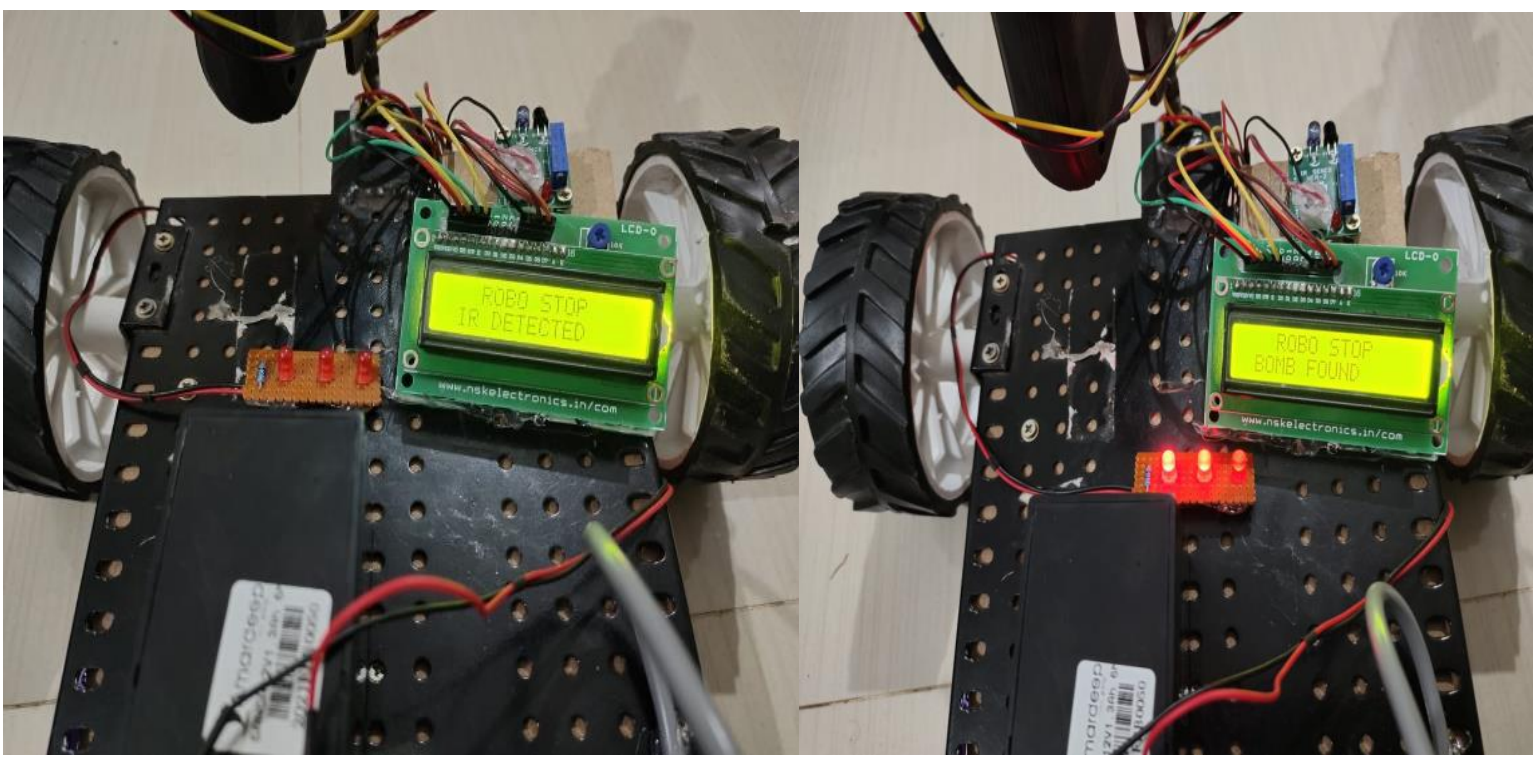

Fig-3 IR Detection

Fig-4 Bomb detection 


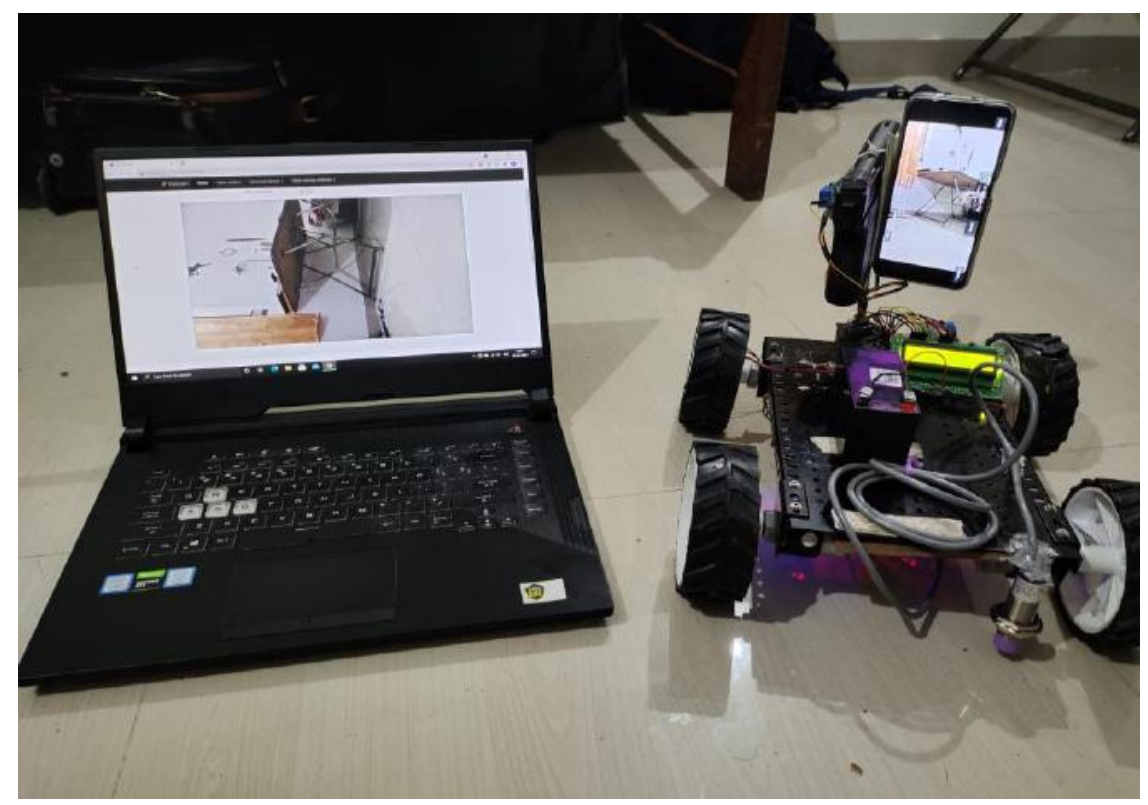

Fig-5 Surveillance through wireless camera

The whole assembly is based on a metal slab(plate) to which holes are drilled through out to fit screws. Four wheels are attached to the sides of the plate and the two rear wheels are connected to the $12 \mathrm{~V}$ DC motors for movement. A cardboard of the same size as that of the metal slab is placed and fixed on top of the slab which aids in fitting of the components. The cardboard is used to provide isolation between components and the metal plate to avoid any losses and as metal plate is not ideal to fit any electronics on top of it. The PIC microcontroller, Relay modules, and all the hardware components are fitted beneath the robot prototype. The wireless camera used here is mobile is fitted to a servo motor which aids in the rotation of the camera and is fitted at the front of the Rover. IR Sensor is attached at the front of the Rover for getting the job of obstacle detection done.

In this project a surveillance rover module which can perform multiple tasks such as object recognition, live video streaming and surveillance. This project proposes a low-cost module which can perform complex tasks such as the object detection with minimum resources. Object detection and surveillance is based on IoT controlled embedded system. The communication between the user and the rover module is achieved through internet via an Blynk android application. This module can be implemented for a variety of surveillance applications.

\section{CONCLUSION}

Triggering mechanism has been successfully tested with 360 rotations to encounter enemy.IR sensor gets activated as soon as it detects obstacles and bomb detector activates when metal found. The efficiency of the system is based on the hardware we have used integrated with microcontroller. The wireless camera will give the report of UGV's surrounding. The system focuses on creating an alert for the controller. The system can be deployed for security and surveillance in border areas.

\section{SOME OF THE ADVANTAGES FROM THE ABOVE RESULTS}

a) The Motorized arm is more effective in the specialized field.

b) Speedy reaction is accomplished.

c) Straightforward in development.

d) Simple to keep up with and fix.

e) Cost of the unit is less when contrasted with other mechanical technology due to PIC microcontroller

f) No fire danger issue due to over stacking.

g) Relatively the activity cost is less.

h) Constant activity is conceivable ceaselessly.

\section{REFERENCES}

[1] R.-S. Run, Y.Jui-Cheng, and T.Cheng-Yu,"A Low Cost Implementation of GPS Guided Driverless cars" in industrial Electronics and applications(ICIEA),2010 the 5th IEEE conference on 2010 pp.1610-1614

[2] Zain Murtaza*, Noaman Mehmood*, Mohsin Jamil*, Yasar Ayaz* "Design and Implementation of Low-Cost Remote-Operated Unmanned Ground Vehicle (UGV)" 978-1-4799-5132-1/14/\$31.00 @2014 IEEE

[3] M. Z. H. Noor, S. A. S. M. Zain, L. Mazalan "Design and Development of Remote-Operated Multi-Direction

This article can be downloaded from here: www.ijaems.com 
Unmanned Ground Vehicle (UGV)" 2013 IEEE 3rd International Conference on System Engineering and Technology, 19 - 20 Aug. 2013, Shah Alam, Malaysia

[4] Sijo Thomas (Author),Dr. Aruna Devi (Author) "Design and implementation of Unmanned Ground Vehicle(UGV) for Surveillance and Bomb Detection using Haptic Arm technology" IEEE International Conference on Innovations in Green Energy and Healthcare Technologies(ICIGEHT'17)

[5] Kunj Gudhka, Aishwarya Kadam, Devika Kale, Manil Rupani, Prof. Tilottama Dhake "War Field Spying Robot Using Wireless Camera" International Journal of Electrical and Electronics Research ISSN 2348-6988 (online) Vol. 4, Issue 1, pp: (85-92), Month: January March 2016

[6] Tarek A. Tutunji, Mohammed Salah-Eddin, Hisham Abdalqader "Unmanned Ground Vehicle Control using IoT" 2020 21st International Conference on Research and Education in Mechatronics (REM) | 978-1-7281-62249/20/\$31.00 @2020 IEEE | DOI: 10.1109/REM49740.2020.9313890 